This item was submitted to Loughborough's Research Repository by the author.

Items in Figshare are protected by copyright, with all rights reserved, unless otherwise indicated.

\title{
Design and operation of an inexpensive, laboratory-scale, continuous hydrothermal liquefaction reactor for the conversion of microalgae produced during wastewater treatment
}

\section{PLEASE CITE THE PUBLISHED VERSION}

https://doi.org/10.1016/j.fuproc.2017.05.006

\section{PUBLISHER}

(C) Elsevier

\section{VERSION}

AM (Accepted Manuscript)

\section{PUBLISHER STATEMENT}

This work is made available according to the conditions of the Creative Commons Attribution-NonCommercialNoDerivatives 4.0 International (CC BY-NC-ND 4.0) licence. Full details of this licence are available at: https://creativecommons.org/licenses/by-nc-nd/4.0/

\section{LICENCE}

CC BY-NC-ND 4.0

\section{REPOSITORY RECORD}

Wagner, Jonathan L., Chien D. Le, Valeska P. Ting, and Christopher J. Chuck. 2019. "Design and Operation of an Inexpensive, Laboratory-scale, Continuous Hydrothermal Liquefaction Reactor for the Conversion of Microalgae Produced During Wastewater Treatment". figshare. https://hdl.handle.net/2134/38377. 


\section{Design and operation of an inexpensive, laboratory-scale,}

2 continuous hydrothermal liquefaction reactor for the

3 conversion of microalgae produced during wastewater

4 treatment

5

6 Jonathan L. Wagner, ${ }^{a, b}$ Chien D. Le, ${ }^{c}$ Valeska P. Ting, ${ }^{d}$ Christopher J. Chuck ${ }^{b *}$

8 a Centre for Doctoral Training in Sustainable Chemical Technologies, Department of Chemical

9 Engineering, University of Bath, Claverton Down, Bath, United Kingdom, BA2 7AY.

$10{ }^{b}$ Department of Chemical Engineering, University of Bath, Claverton Down, Bath, United

11 Kingdom, BA2 7AY.

$12{ }^{\mathrm{C}}$ Department of Oil Refining and Petrochemistry, Hanoi University of Mining and Geology,

13 Hanoi, Vietnam

$14{ }^{\mathrm{d}}$ Department of Mechanical Engineering, University of Bristol, Bristol BS8 1TR, UK

\section{Abstract}

18 Recently, much research has been published on the hydrothermal liquefaction (HTL) of

19 microalgae to form bio-crude, which can be further upgraded into sustainable $3^{\text {rd }}$ generation

20 biofuels. However, most of these studies have been conducted in batch reactors, which are not

21 fully applicable to large-scale industrial production. In this investigation an inexpensive laboratory

22 scale continuous flow system was designed and tested for the liquefaction of microalgae

23 produced during wastewater treatment. The system was operated at a range of temperatures 
$24\left(300^{\circ} \mathrm{C}-340^{\circ} \mathrm{C}\right)$ and flow rates $\left(3-7 \mathrm{ml} \mathrm{min}^{-1}\right)$, with the feed being delivered using high pressure

$25 \mathrm{~N}_{2}$ rather than a mechanical pump. The design incorporated the in-situ collection of solids through 26 a double tube design. The algae was processed at $5 \mathrm{wt} \%$ and the results were compared to those

27 from a batch reactor operated at equivalent conditions. By combining high heating rates with 28 extended reaction times, the continuous system was able to yield significantly enhanced bio-crude 29 yields compared to the batch system. This demonstrates the need for inexpensive continuous 30 processing in the lab, to aid in scale up decision making.

\section{$31 \quad 1$ Introduction}

32 Hydrothermal liquefaction ( $\mathrm{HTL}$ ) of microalgae represents a promising pathway for the production

33 of sustainable, $3^{\text {rd }}$ generation biofuels [1]. It converts the entire algae, including proteins and

34 carbohydrates as well as lipids, and can therefore use faster growing, and cheaper algae than

35 conventional lipid-based processes [2]. It is conducted at high water loadings, typically ranging 36 from around $80 \mathrm{wt} \%$ to $95 \mathrm{wt} \%$ [3], significantly reducing the algae drying requirements, and

37 saving up to $90 \%$ of the total energy costs associated with algal harvesting [4]. Finally, HTL allows

38 a significant proportion of the nitrogen and phosphorus initially present in the algae to partition

39 into the water phase, facilitating the recovery and recycling of these valuable resources [5-7].

40 At the same time, HTL reactions require high pressures to maintain water in its liquid phase, and

41 prevent the latent heat losses associated with vaporisation [1]. Based on steam tables, minimum

42 reaction pressures can be calculated to range from 64 bar to 210 bar for typical reaction

43 temperatures of $280^{\circ} \mathrm{C}$ to $370{ }^{\circ} \mathrm{C}$ [8]. Furthermore, the reaction involves a thick biomass slurry,

44 containing algal particles suspended in an aqueous phase and yields four different product

45 phases (solids, biocrude oil, water and gas), which all need to be collected and separated post

46 reaction. This makes it difficult to carry out this process under continuous flow in a laboratory

47 environment. Consequently, the vast majority of algal HTL research has been conducted within 
48 batch reactors. Although batch systems allow the evaluation and comparison of different

49 feedstocks and reaction conditions, they are not directly applicable to large-scale industrial

50 processing, which heavily relies on continuous flow processes with much higher volumetric

51 productivities [9]. Furthermore, batch systems are unable to provide the same level of control as

52 continuous flow systems and struggle to combine high heating rates, which have been shown to

53 be beneficial for higher biocrude yields [10, 11], with extended reaction times, required to achieve

54 full biomass conversion.

55 Only few continuous liquefaction studies have been published to date [12-14], and have often

56 been restricted to low algae loadings due to operational problems with the feed delivery pump

57 [15], or the formation of blockages within the product collection system [16]. An exception is the

58 work by Elliott et al., who managed to process a biomass slurry with an algae loading of 35 wt $\%$

59 [17]. Their design employed a modified dual syringe pump system to push the algae through the

60 system, and pre-heated the algae feed inside a continuous stirred tank reactor (CSTR), before

61 introducing it into a plug flow reactor (PFR) for further conversion. However, this design is

62 expensive, and may therefore restrict its widespread use by the wider research community.

63 Almost all continuous liquefaction experiments described in the literature were conducted in

64 PFRs, with the exception of the work by López Barreiro et al., who employed a CSTR with a

65 reaction temperature of $350^{\circ} \mathrm{C}$ and a residence time of 15 minutes [18]. However, using this

66 system, overall bio-crude yields were slightly reduced compared to batch reactions, and this was

67 attributed to the cross-reaction between primary intermediates and final reaction products. In

68 contrast, the results from the PFR systems were generally not compared to equivalent batch data,

69 although both Biller et al. [14] and Jazrawi et al. [16] reported increased bio-crude yields as the

70 system flowrates were increased.

71 Another challenge with the HTL process is the tight process economics of producing a relatively

72 low value fuel product. Algae cultivation is relatively expensive and nutrient-intensive [19], and 
73 consequently cost predictions for the production of algal bio-crude via HTL were found to 74 significantly exceed current transportation fuel market prices [20]. It is therefore unlikely that the 75 fuel product will be able to pay for the entire liquefaction process on its own and additional value 76 streams need to be identified and developed which can help to subsidise the fuel production costs.

77 Potential options include the production of by-products with sufficient market share, such as 78 animal feeds, protein supplements, fertilizers or bio-plastics [1], or combining algae cultivation 79 with secondary functions such as carbon sequestration [21-23] or bioremediation [24]. Particularly 80 the combination of algae biomass production with wastewater treatment has the potential to result 81 in substantial cost savings, as well as significantly reducing the overall environmental impact of 82 the two processes [25]. One of the main objectives of wastewater treatment is the removal of 83 nutrients, particularly phosphorus and nitrogen, which can cause eutrophication. Combining 84 wastewater treatment with algae cultivation significantly reduces the amount of additional 85 nutrients required for algae growth [26]. Global municipal waste water production amounts to 86 approximately 300 billion $\mathrm{m}^{3}$, of which just over $50 \%$ is currently treated [27]. Consequently there 87 is huge potential, particularly in less-developed economies, to apply algae cultivation to improve 88 water quality whilst producing a sustainable fuel by-product.

89 In this investigation the design of a continuous lab-based HTL system is presented, specifically 90 designed to represent an inexpensive alternative to laboratory systems already described in the

91 literature. The system was commissioned and operated using a $5 \mathrm{wt} \%$ microalgal slurry produced 92 during the bioremediation of domestic wastewater. During the study the effect of the operating 93 temperature and system flow rate were investigated and compared to the results obtained from a 94 transient batch reactor, operated under equivalent conditions (reaction temperature and heating 95 rates). 


\section{Material and methods}

\section{$97 \quad 2.1$ Biomass preparation and analysis}

98 The algae used for this project was obtained from a collaboration with the Algae Research Group

99 (Department of Biology and Biochemistry, University of Bath) and a local water company, who

100 cultivated the algae to provide tertiary removal of nitrogen and phosphorus from domestic

101 wastewater. As such, the algae (community of locally sourced Scenedesmus and Chlorella

102 strains) was specifically selected for its efficiency in phosphate uptake, as well as its ability to

103 settle out quickly to facilitate its recovery following wastewater treatment.

104 After harvesting, the algae were allowed to settle for a number of days, and the excess water was

105 decanted. The aqueous biomass was subsequently centrifuged to obtain an algal slurry with a 106 biomass concentration of $21.7 \mathrm{wt} \%$, which was separated into $50 \mathrm{~g}$ batches and stored at around $107-4^{\circ} \mathrm{C}$.

108 For each experiment, the required amount of algae was defrosted and diluted with D.I. water to 109 obtain the desired experimental concentration of $5 \mathrm{wt} \%$. The exact algae loading was determined 110 by oven-drying aliquots of the well-mixed algae slurry.

111 The algae ash content was determined using thermogravimetric (TGA) analysis of the dried algae, 112 according to literature precedent [28]. The analysis was conducted in air on a Setaram TG-92 113 microbalance, using a ramp rate of $10^{\circ} \mathrm{C} \mathrm{min}-1$ to $500{ }^{\circ} \mathrm{C}$, followed by a ramp of $20^{\circ} \mathrm{C} \mathrm{min}-1$ to $114900^{\circ} \mathrm{C}$. This analysis was repeated with the same ramp rate on a TG-DSC-EGA analyser 115 (Setaram Setsys Evolution TGA 16/18, Pfeiffer Vacuum Omnistar GSD 320), to determine the 116 gas phase composition. The energy density of the dried algae was measured on an IKA® 117 Calorimeter $\mathrm{C} 1$ analyser, using a $0.5 \mathrm{~g}$ sample, and the weight of the combustion residue was 118 recorded, for comparison. 
119 The carbohydrate assay was carried out according to Taylor [29], incorporating an upfront two-

120 step hydrolysis protocol adapted from Kostas et al. [30]. The lipid content was determined post

121 conversion to fatty acid methyl esters (FAMEs) using GC-MS analysis, as described previously

122 [31]. The protein content was estimated using the algal nitrogen content and applying the standard

123 Jones' factor of 6.25 [32].

\section{$124 \quad 2.2$ Batch reactions}

125 Batch liquefaction reactions were conducted using the same set-up described in our earlier work

$126[24,31]$. Briefly, it consisted of a $50 \mathrm{~mL}$ reactor, fitted with an internal thermocouple and connected

127 to a pressure gauge and vent valve and heated inside a tubular furnace. Each reaction was

128 conducted using approximately $20 \mathrm{~g}$ of the pre-mixed algae slurry ( $5 \mathrm{wt} \%$ algae loading). During

129 reactions, the reactor was placed inside the preheated furnace until the desired reaction

130 temperature $\left(300^{\circ} \mathrm{C}-340^{\circ} \mathrm{C}\right)$ was reached. At this point, the reactor was immediately removed

131 from the furnace and left to cool in ambient air. Different heating rates (at a constant reaction

132 temperature of $320^{\circ} \mathrm{C}$ ) ranging from $10.1^{\circ} \mathrm{C} \min ^{-1}$ to $52.6^{\circ} \mathrm{C} \min ^{-1}$ were obtained by varying the

133 furnace temperature between $500^{\circ} \mathrm{C}$ and $800^{\circ} \mathrm{C}$.

134 Following reactions, the reactor was vented and the reactor contents were decanted through pre135 weighted filter paper, to recover the water phase (filtrate). The aqueous residue, defined as the 136 non-volatile material present in the aqueous phase, was determined gravimetrically after removal

137 of the water by overnight drying of the aqueous phase aliquots in a drying oven $\left(>60^{\circ} \mathrm{C}\right)$. The 138 biocrude phase was recovered by rinsing the reactor wall and filter residue with chloroform until 139 the solvent remained clear and evaporating the solvent under vacuum. Solid yields were 140 determined from the mass of retentate collected on the filter paper.

141 All reactions were conducted in triplicate, and the experimental variation was determined in terms 142 of standard deviations. 


\subsection{Continuous reactor design and operation}

\section{2.3.1 System design}

145 The continuous-flow liquefaction system used for this study can be divided into a number of sub146 sections: a feed delivery system, the liquefaction reactor itself and a product collection and flow

147 control system (Figure 1). The full P\&ID is available in the supporting information.

148 The feed delivery system consisted of two parallel feed reservoirs, pressurised from a high149 pressure nitrogen cylinder and connected via a valve manifold. This design allowed each feed 150 reservoir to be isolated in turn, whilst maintaining flow through the other, to enable topping up with 151 algae, or switch-over from water to algae flow and vice versa, without loss of system flow. The

152 system pressure was controlled to between 160 bar and 165 bar using the pressure regulator on

153 the nitrogen cylinder, limiting the maximum reaction temperature to $347^{\circ} \mathrm{C}$.

154 The reactor consisted of a vertical, double tube design, heated inside a tubular furnace. Cold 155 algae feed entered through the inner tube from the top, where it started to be heated, the products

156 then flowed back up the annulus of the reactor and exited the reactor from the top. This design 157 was chosen to allow fast heating of the algae and collection of the solid products at the bottom of 158 the reactor, preventing their accumulation within the flow line, which would lead to reactor 159 blockages. These solids could then be removed at the end of the reaction. The reaction 160 temperature was determined using a thermocouple (T1) located at the outlet of the inner tube, 161 and a second thermocouple (T2) at the reactor outlet was used to estimate the temperature 162 gradient throughout the reactor.

163 Batch-wise collection of the liquid reaction products at pressure and elevated temperatures was 164 conducted within two parallel, nitrogen-filled collection pots, similar to the configuration previously 165 employed by Elliott et al. [17]. The system flow was controlled indirectly by regulating the flow of 166 nitrogen and reaction gases from the liquid collection pots to a vent line, using a manual gas flow 
167 meter. To protect the flowmeter against overpressure, a pressure-reducing regulator was installed

168 upstream to reduce the pressure below 10 bar. Once one of the pots was full, flow was redirected

169 to the other, and the pot was vented and drained to recover the liquid reaction products.

170 Subsequently, the pot was re-pressured with nitrogen from a separate gas cylinder, and equalized

171 to the system inlet pressure. Following each liquid recovery step, the collected liquid volume and

172 collection time were recorded to monitor and calibrate the system flow rate.

\section{$173 \quad 2.3 .2$ System operation}

174 Prior to each reaction run, the system was started up on distilled water and the gas flow from the 175 outlet was adjusted to achieve liquid flow rates ranging from $3 \mathrm{~mL} \mathrm{~min}^{-1}$ to $7 \mathrm{~mL} \mathrm{~min}^{-1}$. Next, the 176 furnace temperature was increased gradually until the desired reaction temperature (300 $177340^{\circ} \mathrm{C}$ ) was obtained, as measured by $\mathrm{T} 1$, the thermocouple located at the bottom of the inner

178 reaction tube. Once steady state was reached, the reaction was started by switching system flow 179 from distilled water to the pre-mixed algae slurry. After flowing a total of $1 \mathrm{~L}$ of a $5 \mathrm{wt} \%$ algae 180 slurry, the system was maintained at reaction conditions, whilst being purged with distilled water 181 for another two hours, until the liquid at the system outlet started to run clear. At this point, the 182 furnace was turned off and water flow was maintained until the system temperature reduced to a 183 safe level, at which point it was isolated and allowed to cool overnight. Depending on the system 184 flow rate, the liquid collection pots were drained every 15 to 30 minutes, to prevent overflow of 185 the reaction liquids into the gas lines. The total collected liquid volume was recorded to determine 186 the remaining feed volume, and prevent the system from running dry.

187 A repeat run at the medium reaction temperature of $320^{\circ} \mathrm{C}$ and flowrate of $5 \mathrm{~mL} \mathrm{~min}^{-1}$ was used 188 to estimate the experimental variation of the system. 


\subsubsection{Product recovery}

190 Neither the gas yield nor the composition was investigated as the study focused on liquid phase

191 and solid products. Bio-crude and water products recovered from the liquid collection pots were 192 collected and separated using vacuum filtration through pre-weighed filter paper. After each 193 collection interval, a $20 \mathrm{~mL}$ aliquot of reaction water was re-filtered by gravity, to ensure full 194 removal of any entrained solids, and retained for further analysis. Any remaining water was re195 filtered under vacuum and combined into two separate samples: water collected during algae flow 196 and water collected post reaction, during water purging. The bio-crude product was recovered by 197 washing all filter papers with chloroform and combined into a single fraction. Solid carry-over to 198 the outlet was determined by re-weighing the dried filter papers following bio-crude removal.

199 At the end of each reaction run, the system was fully dismantled to allow the recovery of solids 200 and bio-crude product residue from the reactor and the system pipework. The reactor contents 201 were filtered and thoroughly washed with water and chloroform to obtain the solid products and a 202 heavy bio-crude fraction, labelled 'heavy bio-crude'. Chloroform washing of the reactor outlet

203 piping and collection pots allowed the recovery of 'pipe bio-crude ', which was eventually 204 combined with the bio-crude product from the system outlet to form the 'light bio-crude' fraction.

205 Product yields were calculated on a dry biomass basis, without further correction for the ash 206 content.

2072.4 Product analysis

208 Elemental $(\mathrm{CHN})$ analysis of the bio-crude samples was carried out externally on a Carlo Erba 209 Flash 2000 Elemental Analyser. For the continuous reactions, the light and heavy bio-crude 210 fractions were analysed separately, before calculating weighted averages to determine the 211 elemental distribution to the total biocrude phase. In the case of the batch reactions, only the most 
212 representative of the three repeats (yield closest to average) was analysed for each reaction

213 condition.

214 The water content of the combined bio-crude from all continuous HTL reactions was determined

215 by Karl Fischer titration. Prior to analysis, the sample was diluted in chloroform to $2 \mathrm{wt} \%$, and

216 calibrated against the chloroform water content. The energy density of the combined bio-crude

217 was measured on an IKA® Calorimeter $\mathrm{C} 1$ analyser, using a $0.5 \mathrm{~g}$ sample. This analysis was also

218 used to estimate the ash content of the bio-crude and verified against the results from TGA.

219 The concentration of ammonium ions in the water phase was determined using a Randox Urea

220 analysis test kit. Prior to analysis, the samples were diluted with D.I. water to a concentration of

$22120 \mathrm{vol} \%$. Subsequently $10 \mu \mathrm{L}$ of sample was reacted for 5 min with $1000 \mu \mathrm{L}$ of a urease reactant,

222 followed by the addition of $200 \mu \mathrm{L}$ of sodium hypochlorite solution to induce the colour change.

223 Finally, the sample absorbance was measured at $600 \mathrm{~nm}$ and calibrated using a reagent blank

224 and standard solution.

225 Total organic carbon (TOC), total inorganic carbon (IC) and total nitrogen (TN) of the water phase

226 products were determined on a Shimadzu Corp. total organic carbon analyser (TOC-L), linked to

227 a total nitrogen analyser (TNM-L) and autosampler (ASI-L). Prior to analysis, samples were

228 diluted with D.I. water to 12.5 vol\%. For the continuous reactions, the total carbon and nitrogen

229 recovery to the water phase was estimated using the carbon and nitrogen concentrations in the

230 combined water phase obtained during the entire reaction period.

\section{Results and discussion}

\section{$232 \quad 3.1$ Biomass characterization}

233 Thermogravimetric analysis (TGA) of the dried algae resulted in a total weight loss of $79.2 \mathrm{wt} \%$, 234 associated with the loss of residual moisture (5.0 wt\%), two exothermic peaks at temperatures of 
$235350^{\circ} \mathrm{C}$ and $545{ }^{\circ} \mathrm{C}(65.1 \mathrm{wt} \%)$ and an endothermic peak at $831^{\circ} \mathrm{C}(9.1 \mathrm{wt} \%$, supporting

236 information). The two exothermic peaks can be associated with the combustion of organic

237 biomass components, confirmed by the detection of both carbon dioxide and water during TG-

238 MS analysis, whereas the only gas released over the high-temperature endothermic peak was

239 carbon dioxide. Therefore it is likely that this peak was associated with the thermal decomposition

240 of carbonates, as previously detected during TGA analysis of macroalgae [33], and suggests that

241 the wastewater derived algae sequestered atmospheric carbon in both organic and inorganic

242 form. As the ash content is generally defined as the inorganic biomass fraction, it was calculated

243 to include these carbonates by using the residual sample weight at $650{ }^{\circ} \mathrm{C}$. The resulting value of

$24429.9 \mathrm{wt} \%$ compares to a residue weight of only $20.8 \mathrm{wt} \%$ at $900{ }^{\circ} \mathrm{C}$ and a combustion residue of

$24530.1 \%$ using bomb calorimetry.

246 Biochemical compositional analysis of the algae showed that it was predominantly composed of

247 proteins, and contained only low amounts of lipids and carbohydrates (Table 1). Overall, the

248 contribution of these three major biochemical compounds was $59.1 \mathrm{wt} \%$, with an ash content of

24929.9 wt\%., resulting in an energy density of $12.72 \mathrm{MJ} \mathrm{kg}^{-1}$.

$250 \quad 3.2$ System design

251 The system was specifically designed to provide a lower-cost alternative to the HTL systems

252 already used in the literature. During the commissioning process, a number of operational

253 challenges were encountered, which required significant modifications to the initial design, to

254 allow the processing of the entire biomass inventory. Particular challenges were the formation of

255 blockages within the reactor tube itself, and large fluctuations in system flow and temperature, as

256 a result of control valve blockages. In this section, the final design is discussed and compared to

257 alternative systems in the literature. 
259 To date, most continuous HTL systems described in the literature have employed high-pressure

260 mechanical pumps to push the algae feed through the system. However, even though mechanical

261 pumps are the expected method of choice for larger-scale operation, laboratory-scale pumps, that

262 can generate the high required reaction pressure as well as being able to handle the semi-solid

263 algal particles in the feed, (such as the modified dual syringe pump system used by Elliott et al.

264 [17]) are expensive, and still not directly applicable to industrial processing. Alternative pumps

265 used in the literature have either exceeded the desired laboratory-scale flow rates, such as the

266 triplex piston pump system used by Jazrawi et al. [16] and Cole et al. [12] (15-90 $\left.\mathrm{L} \mathrm{h}^{-1}\right)$ or have

267 struggled to process elevated biomass concentrations, such as the HPLC pump used by Patel

268 and Hellgardt [15].

269 In contrast, by using high-pressure nitrogen as the algae driving force, our design eliminates the

270 requirement of a mechanical pump completely, and thereby reduces the risk of blockages within

271 the pump cavities as well as representing a lower-cost lab scale alternative to existing HTL

272 systems. It provides a high degree of flexibility, both in terms of flow rate and feed pressure, and

273 the double feed cylinder arrangement allows continuous feeding of algae. Despite initial concerns

274 of nitrogen break-through, resulting in flow fluctuations, the final design was found to be able to

275 deliver a constant liquid flowrate throughout the entire reaction period, as determined from the

276 liquid accumulation within the liquid collection pots, as well as constant reaction temperatures

277 (supplementary information).

278 A disadvantage is the lack of the precise metering functionality of some of the mechanical pumps,

279 and consequently the system flow rate had to be controlled separately. Furthermore, as nitrogen

280 is a compressible fluid, variations in the pressure drop through the system could have a larger

281 effect on the algae flow rate through the system. This problem was mitigated by controlling the 282 product flow from the outlet instead. 


\subsubsection{Reactor configuration}

284 Consistent with the majority of continuous HTL systems described in the literature, our design 285 employed a modified PFR to conduct the liquefaction reaction. However, to the best of our 286 knowledge this is the first time a double-tube design to allow the collection of the solid reaction 287 products within the reactor itself has been applied to this reaction. The main reason for adapting 288 this arrangement was to address operational problems caused by the extensive formation of 289 blockages within a single-pass, up-flow reactor. These blockages were predominantly attributed 290 to the accumulation of solid products within the reactor tube, possibly as a result of insufficient 291 flow velocities through the system to allow full fluidisation of this phase.

292 No previous publication reported significant issues with blockages formed within the reactor, 293 however it should be noted that in many cases the algae loadings were significantly lower than in 294 the present work [13, 15, 34], or the authors employed a co-solvent to prevent plugging issues in 295 the first place $[12,15]$. An exception is the work by Elliott et al., who processed a feed with an 296 algae concentration of up to $35 \mathrm{wt} \%$, however this group employed a CSTR to pre-heat the algae 297 feed from $133^{\circ} \mathrm{C}$ to the final reaction temperature before allowing the reaction to be completed 298 in a PFR [17]. It should also be noted that the algal biomass used in most previous HTL reactions 299 was less challenging to process than the wastewater algae used in this project, which contained 300 a very high ash content ( $30 \%)$, allowing the algae to settle out quickly following wastewater 301 treatment. This high ash content may have contributed to the severity of the reactor blockages 302 experienced with our initial design.

303 An additional benefit of the double-tube reactor is that it combines very fast heating rates with 304 extended reaction times, and reduces the presence of hot-spots at the reactor wall, which might 305 catalyse the formation of radicals, which in turn could initiate polymerisation reactions. Based on 306 the range of system flow rates $\left(3 \mathrm{~mL} \mathrm{~min}^{-1}\right.$ to $\left.7 \mathrm{~mL} \mathrm{~min}^{-1}\right)$, heating rates were estimated to have 307 ranged from $28.8^{\circ} \mathrm{C} \min ^{-1}$ to $67.6^{\circ} \mathrm{C} \mathrm{min}{ }^{-1}$, whilst the residence time of the hot reagents/products 
308 in the outer tube varied between 17.7 and 41.8 minutes. The design also allowed the partial heat

309 recovery from the hot reaction product in the reactor, without causing the plugging problems

310 reported by Elliott et al. when pre-heating a lignocellulosic reaction feed above $133^{\circ} \mathrm{C}$ [17]. At the

311 same time, temperature drops between $45^{\circ} \mathrm{C}$ and $58^{\circ} \mathrm{C}$ were recorded between the bottom of

312 the inner tube and the outlet of the reactor.

313 The solid retention within the reactor exceeded $95 \%$ for all reactions, with little correlation to the

314 selected reaction conditions (temperature and flow). This suggests that gravity settling was highly

315 effective in the recovery of this solid fraction. Even so, the solid capacity of the reactor is limited,

316 and therefore in future designs it may be necessary to incorporate a solid removal system to allow

317 extended system operation.

\section{$318 \quad 3.2 .3 \quad$ Product collection and flow control}

319 Prior to designing the liquid collection system, consisting of two parallel, nitrogen-filled collection

320 pots, an attempt was made to control the system flow directly, using a liquid flowmeter at the

321 system outlet. However, the high viscosity of the biocrude at room temperature resulted in the

322 clogging of the control valves, causing significant fluctuations of the system flow. Similar problems

323 were previously reported by Jazrawi et al., who experienced significant pressure fluctuations as

324 a result of transient blockages of their back-pressure control valve [16]. In contrast, controlling the

325 system backpressure on the outflow of gas avoided the requirement of having to pass the viscous

326 biocrude through the restrictions within a control valve. Although this design required the batch-

327 wise removal of liquid products, followed by repressurisation of the collection pots, further

328 modifications to install a level controller within the collection pot would allow the continuous

329 recovery of the liquid products. Furthermore, flow control could be improved by installing a liquid

330 flowmeter to set the operating variable of an automatic control valve at the gas outlet. 


\subsubsection{System operation}

332 During the operation of the system, depending on the reaction temperature and the system flow 333 rate of any particular experiment, the collection pot temperature varied from $56.3^{\circ} \mathrm{C}$ to $125.9{ }^{\circ} \mathrm{C}$,

334 as a result of different residence times, and therefore different heat losses to the environment.

335 The percentage of the total recovered bio-crude fraction collected from the outlet was found to be

336 directly proportional to this temperature, whereas the opposite trend was observed for the bio-

337 crude obtained from the reactor outlet piping, post reaction (supplementary information). These

338 trends could be related to increases in the biocrude viscosity and reduced miscibility with the

339 water phase, as the collection temperature is reduced. However, all reactions were conducted

340 with the same amount of algae, and consequently, it is not known whether bio-crude accumulation

341 within the system pipework remained constant over the entire reaction period, or whether it

342 reached a saturation point, after which all additional bio-crude exited from the system. Continuous

343 bio-crude accumulation would eventually result in the formation of system blockages, and

344 therefore system operation should be investigated over longer reaction periods. As the partitioning

345 between bio-crude remaining in the system pipework and bio-crude recovered from the outlet

346 appeared to depend mostly on the collection temperature, these two fractions were combined into

347 a single 'light-biocrude' phase.

348 In contrast, the fraction of bio-crude recovered from the reactor was found to be independent of

349 the collection temperatures. As this bio-crude cannot be easily recovered from the system during

350 continuous flow and was found to be much more viscous than the biocrude fractions recovered

351 from the outlet and the reactor pipework, which suggests a different chemical composition, it was

352 kept as a separate, 'heavy bio-crude' phase, further GC-MS analysis confirmed the different 353 chemical nature of both bio-crude samples (see supporting information).

354 Using our system, it was possible to consistently process $1 \mathrm{~L}$ of a $5 \mathrm{wt} \%$ algae slurry, whilst 355 maintaining constant reaction temperatures and system flow rates. Whilst the system required a 
356 lot of operator input, it represents a significantly lower cost alternative to the systems already used

357 in the literature, making it feasible as a bench-scale laboratory system.

\section{$358 \quad 3.3 \quad$ Batch conversion}

359 Prior to converting the wastewater-derived algae within the continuous HTL system, a number of

360 baseline reactions were conducted in a batch system to determine the effect of reaction

361 temperature and heating rate on the resulting product distribution. Batch reactions were

362 conducted under transient conditions, which means that the reactors were removed from the

363 furnace as soon as the desired reaction temperature was reached, giving an effective reaction

364 time of 0 minutes. This approach allows much faster heating rates than the more commonly used

365 isothermal systems, where the reaction temperature is maintained for a prolonged period of time.

\section{3.3.1 Effect of reaction temperature}

367 The conversion of the wastewater-derived algae was studied at three different temperatures

$368\left(303^{\circ} \mathrm{C}, 322^{\circ} \mathrm{C}\right.$ and $\left.339^{\circ} \mathrm{C}\right)$ with a constant furnace temperature of $700{ }^{\circ} \mathrm{C}$, resulting in averaged 369 heating rates ranging from $33.8^{\circ} \mathrm{C} \mathrm{min}{ }^{-1}$ at $339^{\circ} \mathrm{C}$ to $37.6^{\circ} \mathrm{C} \mathrm{min}{ }^{-1}$ at $303^{\circ} \mathrm{C}$. As the reaction 370 temperature was increased from $303^{\circ} \mathrm{C}$ to $339^{\circ} \mathrm{C}$, solid yields were found to reduce from 37143.6 wt\% to 38.2 wt\% (Figure 2a). This is consistent with our earlier work [31] and can be

372 associated with an increase in algae conversion resulting in reduced solid retention of the organic

373 biomass components. As the reaction temperature was increased from $303^{\circ} \mathrm{C}$ to $321^{\circ} \mathrm{C}$, the 374 water phase residue yield also experienced a remarkable decrease from $29.9 \mathrm{wt} \%$ to $20.7 \mathrm{wt} \%$, 375 which could be partially attributed to the simultaneous increase in biocrude yield (12.1 wt\% to $37617.1 \mathrm{wt} \%)$ and a reduction in the overall mass balance closure from $85.5 \%$ to $79.2 \%$. The

377 unaccounted product fraction can be assigned to gaseous products, as well as volatile organic 378 reaction products present in the aqueous phase, which are lost during the drying of the water 379 phase residue. As the reaction temperature was increased further to $339^{\circ} \mathrm{C}$, the water residue 
380 yield increased by $3.3 \mathrm{wt} \%$, closely matching the simultaneous reduction in solid yields (41.5 wt\%

381 to $38.2 \mathrm{wt} \%$ ), although a slight decrease in bio-crude yield (17.1 wt\% to $15.9 \mathrm{wt} \%$ ) was also

382 experienced over the same temperature range.

383 The highest carbon (30.2\%) and hydrogen (27.6\%) recoveries to the biocrude were achieved at

384 the medium reaction temperature, producing a combined bio-crude (heavy + light) with a nitrogen

385 content of $4.0 \mathrm{wt} \%$, lower than the biocrudes obtained at the other two reaction temperatures

386 (Figure 2b). Consistent with the low overall bio-crude yield, the carbon and hydrogen recoveries

387 obtained at $303^{\circ} \mathrm{C}$ were much lower, although the difference in nitrogen recovery was much

388 smaller, indicating that a large proportion of nitrogen-containing compounds was already

389 incorporated into the biocrude at low reaction temperatures.

390 However, when increasing the reaction temperature from $322^{\circ} \mathrm{C}$ to $339^{\circ} \mathrm{C}$, the hydrogen and 391 carbon distribution to the bio-crude reduced, whereas the nitrogen retention increased, 392 suggesting that nitrogen containing compounds continued to be converted into biocrude 393 components at all reaction temperatures. These findings are consistent with previous studies [11, $39416,35]$ and suggest that significantly increasing the reaction temperatures above $320{ }^{\circ} \mathrm{C}$ had no 395 beneficial impact on the biocrude recovery.

396 Contrary to trends for the biocrude, the carbon and nitrogen recoveries to the water phase 397 reduced with increasing reaction temperatures (Figure 2c). Whilst the maximum combined carbon 398 recovery to the water and bio-crude phases of $59.9 \%$ was still obtained at $322{ }^{\circ} \mathrm{C}$, the combined 399 nitrogen recovery decreased from $77.5 \%$ to $75.5 \%$ as the reaction temperature was raised from $400303^{\circ} \mathrm{C}$ to $339^{\circ} \mathrm{C}$. A potential explanation for these trends is that the majority of nitrogen 401 partitioned from the solid phase to the other phases at the lowest reaction temperature, whereas 402 carbon transfer from the solid to the aqueous and bio-crude phases continued up to a temperature 403 of $322^{\circ} \mathrm{C}$, beyond which carbon started to be lost to the gas phase. It can also be noted, that the 
404 total nitrogen content in the aqueous phase is a very good match to the ammonium ion content, 405 indicating that very few organic nitrogen compounds were present.

\section{3.3.2 Effect of heating rate}

407 Four different heating rates, ranging from $10.1^{\circ} \mathrm{C} \cdot \mathrm{min}^{-1}$ to $52.6^{\circ} \mathrm{C} \cdot \mathrm{min}^{-1}$ were obtained by varying 408 the furnace temperature between $500^{\circ} \mathrm{C}$ and $800^{\circ} \mathrm{C}$. It should be noted that these heating rates 409 represent average, rather than absolute values, as they dropped off as the reaction temperature 410 was approached, particularly for the lower furnace temperatures. All reactions were conducted to 411 a maximum reaction temperature of $320^{\circ} \mathrm{C}$.

412 At the two lower heating rates, the solid yields remained approximately constant around 40 wt\%, 413 but increased slightly to $41.5 \mathrm{wt} \%$ and $42.8 \mathrm{wt} \%$ as the heating rates were increased to 35.2 and $41452.6^{\circ} \mathrm{C} \mathrm{min}{ }^{-1}$, respectively (Figure 3a). Bio-crude yields, in turn, increased almost linearly from

$41514.9 \mathrm{wt} \%$ to $17.1 \mathrm{wt} \%$ as the heating rates were raised from $10.1{ }^{\circ} \mathrm{C} \mathrm{min}^{-1}$ to $35.2{ }^{\circ} \mathrm{C} \mathrm{min} \mathrm{m}^{-1}$, but 416 dropped off to $13.5 \mathrm{wt} \%$ at the highest heating rate of $52.6^{\circ} \mathrm{C} \mathrm{min}{ }^{-1}$. The water residue yields 417 showed the opposite trend to bio-crude yields, decreasing from $24.7 \mathrm{wt} \%$ at the lowest heating 418 rate to $20.7 \mathrm{wt} \%$ at $35.2^{\circ} \mathrm{C} \mathrm{min}^{-1}$, before increasing to $27.7 \mathrm{wt} \%$ at the highest heating rate.

419 The increase in solid yields at the higher heating rates can be explained by the reduced reaction 420 time, resulting in the incomplete conversion of the organic biomass components. Bio-crude and 421 residue yields, in turn, appeared to be closely related. As heating rates increased from $42210.1^{\circ} \mathrm{C} \min ^{-1}$ to $35.2^{\circ} \mathrm{C} \cdot \mathrm{min}^{-1}$, the product distribution shifted from water phase residue towards 423 bio-crude, but at the highest heating rate, the bio-crude yields were at their lowest, whilst 424 maximum water phase residue yields were obtained.

425 The general trend of increasing bio-crude yields with increasing heating rates is consistent with 426 previous results by Faeth et al. [10], and Garcia Alba et al. [11]. Where the maximum bio-crude 427 yields obtained at the highest heating rate, were significantly higher than optimized bio-crude 
428 yields at lower sandbath temperatures [10]. A subsequent publication by the same authors [36]

429 reported that biocrude yields increased when the total reactor loading was reduced from 60 vol\%

430 to 10 vol\%. These differences were explained by an increase in the apparent biomass

431 concentration, as the same quantity of water needed to evaporate to generate the reaction

432 pressure. An alternative explanation is that the reactions became kinetically and heat-transfer

433 limited as the reaction volume was increased. This could also explain the sharp drop in biocrude

434 yields at the highest heating rate observed in the present study and suggests that the reaction

435 time was potentially too short to achieve full conversion of the water phase residue phase into

436 biocrude components.

437 As expected from the bio-crude yields, the highest carbon and hydrogen retentions were obtained

438 at the heating rate of $35.2{ }^{\circ} \mathrm{C} \min ^{-1}$ (Figure $3 \mathrm{~b}$ ). The reduction in carbon, hydrogen and nitrogen

439 retentions at lower heating rates can be attributed mostly to the reduction in bio-crude yields,

440 whilst the overall bio-crude composition remained relatively constant. In contrast, the bio-crude

441 obtained at the highest heating rate had a noticeably higher nitrogen content of 4.8 wt $\%$ than the

442 bio-crude obtained at a heating rate of $35.2^{\circ} \mathrm{C} \min ^{-1}(4.0 \mathrm{wt} \%)$. This is similar to the results

443 obtained at the lowest reaction temperature and suggests that nitrogen containing compounds

444 preferentially partition to the biocrude under less severe reaction conditions. It is also possible

445 that some of this nitrogen is removed via denitrogenation reactions at higher reaction

446 temperatures, or longer residence times, counteracting the further transfer of nitrogen containing

447 components from the aqueous to the biocrude phase [37].

448 Carbon recoveries to the aqueous phase reduced from $31.9 \%$ to $29.7 \%$ as the heating rate was

449 reduced from $52.6{ }^{\circ} \mathrm{C} \mathrm{min}-1$ to $35.2{ }^{\circ} \mathrm{C} \mathrm{min}-1$ (Figure $3 \mathrm{c}$ ) and reduced further to $27.3 \%$ for a 450 heating rate of $21.8^{\circ} \mathrm{C} \mathrm{min}^{-1}$. The highest combined carbon recovery to the aqueous and bio451 crude phases of $59.9 \%$ was therefore obtained at the heating rate of $35.2{ }^{\circ} \mathrm{C} \min ^{-1}$, compared to 452 recoveries of less than $55.6 \%$ at all other heating rates. This indicates incomplete carbon transfer 
453 from the solid to the aqueous and bio-crude phases at very high heating rates, whilst increased

454 reaction times increased the transfer of carbon to the gas phase In contrast, both the nitrogen

455 recovery to the aqueous phase alone (69.4\% to $61.4 \%$ ) and combined nitrogen recovery to the

456 aqueous and bio-crude phases (80.0\% to $71.9 \%)$ reduced steadily as the heating rates were

457 reduced from $52.6^{\circ} \mathrm{C} \min ^{-1}$ to $10.1^{\circ} \mathrm{C} \mathrm{min}$. . Once again, the nitrogen content in the water phase

458 could be almost exclusively assigned to ammonium ions.

\section{3.3.2.1 Reaction mechanism}

460 The trends in water phase residue and biocrude yields suggest that the two product phases are

461 closely related. Low reaction temperatures and very high heating rates appeared to favour the

462 formation of molecules that partition into the aqueous phase, which were further converted into

463 biocrude as the reaction severity is increased [38]. At the same time, some of the nitrogen

464 incorporated into the biocrude at low temperatures and high heating rates were removed via

465 denitrogenation, reducing the nitrogen content of the bio-crude phase, and the aqueous phases,

466 and resulting in the formation of more volatile reaction products, which were not recovered.

467 The results suggest a stepwise reaction mechanism; first the algae is broken up into water soluble

468 compounds, which then further react to form the biocrude and more volatile reaction products.

469 This is consistent with the previously suggested Maillard type reaction pathways, where

470 carbohydrates and proteins in the biomass are first decomposed into sugars and amino acids,

471 which then further react via dehydration reactions to form heavier, water-insoluble compounds

$472[39,40]$.

473 However, the algae decomposition into intermediates and their subsequent reactions to form bio-

474 crude, water phase and gaseous products, can follow many different pathways and the ultimate

475 product distribution depends on the relative reaction kinetics between these pathways. Low

476 heating rates would therefore favour reactions with lower activation energies, consuming a

477 significant proportion of the reaction intermediates before the temperature rises to a level where 
478 higher energy reactions can occur. Based on the trends observed for biocrude yields and heating 479 rate, the reactions resulting in the formation of biocrude appear to have higher activation energies 480 than the reactions resulting in the formation of alternative product phases.

481 However, at the highest heating rates, the reaction time appears to be insufficient to allow full 482 conversion of the biomass or the reaction intermediates, resulting in a sharp drop in biocrude 483 yields. Unfortunately, the transient batch reactors used in this study did not allow the combination

484 of high heating rates with extended reaction times, potentially limiting the maximum biocrude yield 485 that could be obtained. Consequently, the continuous system, which combines higher heating 486 rates with extended reaction times, was expected to provide more favourable product 487 distributions.

\section{$488 \quad 3.4$ Continuous conversion}

489 The continuous reaction system was operated at four different temperatures $\left(302^{\circ} \mathrm{C}, 320^{\circ} \mathrm{C}\right.$, $490328^{\circ} \mathrm{C}$ and $\left.344{ }^{\circ} \mathrm{C}\right)$ and three different flow rates $\left(3 \mathrm{~mL} \mathrm{~min}{ }^{-1}, 5 \mathrm{~mL} \mathrm{~min}^{-1}\right.$ and $\left.7 \mathrm{~mL} \mathrm{~min}^{-1}\right)$. These 491 conditions corresponded to heating rates ranging from $28.8^{\circ} \mathrm{C} \mathrm{min}-1$ to $67.6^{\circ} \mathrm{C} \mathrm{min}{ }^{-1}$, comparable 492 to the heating rates achieved with the batch system $\left(10.1^{\circ} \mathrm{C} \cdot \mathrm{min}^{-1}\right.$ to $\left.52.6^{\circ} \mathrm{C} \cdot \mathrm{min}^{-1}\right)$. water

\section{3.4.1 Effect of reaction temperature}

494 The effect of the reaction temperatures on the product distribution was studied at a constant 495 system feed flow rate of $7 \mathrm{~mL} \mathrm{~min}{ }^{-1}$ (Figure 4a). Consistent with the findings from the batch study, 496 solid yields were generally lower at higher reaction temperatures, although there was a high 497 degree of experimental uncertainty, related to the difficulty of fully recovering the solid phase from 498 the bottom of the reactor. Water phase residue yields followed a clearer trend, decreasing steadily 499 from $19.8 \mathrm{wt} \%$ at $302{ }^{\circ} \mathrm{C}$ to $13.4 \mathrm{wt} \%$ at $344{ }^{\circ} \mathrm{C}$. The trends in biocrude yields appeared to be 500 more complex. Whilst the maximum heavy bio-crude yields (5.8 wt\%) were obtained at the lowest 501 reaction temperature of $302{ }^{\circ} \mathrm{C}$, they decreased to a minimum of $3.5 \mathrm{wt} \%$ at $320^{\circ} \mathrm{C}$, before 
502 recovering to $4.5 \mathrm{wt} \%$ and $5.2 \mathrm{wt} \%$ at reaction temperatures of $328^{\circ} \mathrm{C}$ and $344{ }^{\circ} \mathrm{C}$, respectively.

503 Light bio-crude yields were lowest at the minimum reaction temperature of $302{ }^{\circ} \mathrm{C}(14.3 \mathrm{wt} \%)$, 504 and remained approximately constant around $15 \mathrm{wt} \%$ to $16 \mathrm{wt} \%$ for the other three reaction 505 temperatures.

506 The initial reduction in the heavy bio-crude yields from $5.8 \mathrm{wt} \%$ to $3.5 \mathrm{wt} \%$, as the reaction 507 temperatures were increased from $302{ }^{\circ} \mathrm{C}$ to $320^{\circ} \mathrm{C}$, closely matches the simultaneous increase 508 in light bio-crude yields from $14.3 \mathrm{wt} \%$ to $16.0 \mathrm{wt} \%$. This could be the result of increased cracking 509 reactions of heavy bio-crude components to form lighter, less viscous compounds, which were 510 carried over into the light bio-crude phase. Conversely, the subsequent increase in heavy bio511 crude yields at higher reaction temperatures could be caused by the volatilisation of heavy 512 organics bound to the solid phase product.

513 Based on the continuous conversion results and contrary to the batch study, the aqueous phase 514 residue yields appeared to show little correlation to the biocrude yields. Instead the decrease in 515 this phase could be mostly attributed to a decrease in overall recovered product from $69.5 \mathrm{wt} \%$ 516 to $63.0 \mathrm{wt} \%$, suggesting the formation of more volatile reaction products at higher reaction 517 temperatures, partitioning into the gas phase, or lost during the recovery of the water phase 518 residue. However, it is possible that these volatile products were formed from the bio-crude phase 519 instead, as a result of gasification, denitrogenation and deoxygenation reactions, counteracting 520 the additional conversion of the water-phase residue into the light bio-crude product phase. It 521 should also be noted that, contrary to the batch study, bio-crude yields did not reduce at higher 522 reaction temperatures, which could indeed suggest further conversion of the water phase residue 523 into the light bio-crude phase.

524 To investigate this in more detail, the carbon, hydrogen and nitrogen balance to the bio-crude 525 phase was calculated from the elemental analysis of the two biocrude fractions (Figure 4b). 526 Increasing the reaction temperature from $302{ }^{\circ} \mathrm{C}$ to $320^{\circ} \mathrm{C}$ resulted in a significant increase in 
527 carbon retention from $35.0 \%$ to $40.8 \%$, but at higher temperatures the carbon retention remained 528 approximately constant. Nitrogen retentions reduced steadily from $16.3 \%$ at $302{ }^{\circ} \mathrm{C}$ to $11.7 \%$ at $529344^{\circ} \mathrm{C}$, which is opposite to the trend observed during the batch experiments. This could suggest 530 that the extended residence time in the continuous flow reactor allowed more denitrogenation

531 reactions to take place. Finally, the hydrogen retention was highest at $320^{\circ} \mathrm{C}$ and dropped sharply

532 as the reaction temperature was increased further. This could be explained by the participation of

533 hydrogen in the denitrogenation pathway to form ammonia and is consistent with the steady

534 increase in the yield of ammonia in the water phase from $1.7 \mathrm{wt} \%$ to $3.0 \mathrm{wt} \%$, corresponding to a

535 nitrogen recovery of $23.2 \%$ and $41.1 \%$, respectively, as the reaction temperature was raised

536 from $302{ }^{\circ} \mathrm{C}$ to $344^{\circ} \mathrm{C}$ (Supplementary information).

537 The carbon recovery to the water phase steadily decreased from $34.8 \%$ to $26.8 \%$ as the reaction 538 temperature was increased from $302{ }^{\circ} \mathrm{C}$ to $328^{\circ} \mathrm{C}$, consisting almost exclusively of organic 539 carbon, resulting in a combined carbon recovery to the bio-crude and water phases of $71.6 \%$ to

$54064.5 \%$. Presumably, the remaining carbon was distributed between the solid phase, containing

541 most of the inorganic carbon in the algae $(\sim 10 \mathrm{wt} \%)$ and the gas phase $\left(\mathrm{CO}_{2}\right)$. The nitrogen

542 recovery to the water phase ranged from $87.5 \%$ at $302{ }^{\circ} \mathrm{C}$ to $73.2 \%$ at $328^{\circ} \mathrm{C}$, before recovering

543 to $82.1 \%$ at the highest reaction temperature, corresponding to combined nitrogen recoveries

544 between $103.8 \%$ and $86.7 \%$. These high mass balance closures suggest very little nitrogen

545 distribution to the solid or gas phases.

\section{$546 \quad 3.4 .2$ Effect of system flow rate}

547 To study the effect of the system flow rate on the product distribution, the reaction temperature 548 was kept constant at $320^{\circ} \mathrm{C}$ (Figure $5 a$ ). Increasing the flow rate from $3.0 \mathrm{~mL} \mathrm{~min}^{-1}$ to $6.9 \mathrm{~mL} \mathrm{~min}$

$549{ }^{1}$ resulted in a clear increase in solid yields from $27.7 \mathrm{wt} \%$ to $35.2 \mathrm{wt} \%$. This is consistent with the 550 results from the batch study, where higher heating rates were found to produce more solid, 551 probably as a result of reduced reaction times. However, the solid yields from the continuous 
552 system (maximum of $35.2 \mathrm{wt} \%$ ) were much lower than those from the batch reactor (minimum of

$55339.7 \mathrm{wt} \%$ ), and at the lowest flow rate approached the value of the initial algae ash content,

554 suggesting full conversion of the organic biomass fraction. This is unsurprising, as even at the

555 fastest flow rate, the reaction time in the continuous system (17.8 min) significantly exceeded the

556 reaction times obtained within the batch system. Furthermore, the solid products remained in the

557 bottom of the reactor for a period of several hours, allowing the reaction to proceed even after the

558 algal flow was stopped. Consequently, the increase in solid yields at higher system flows cannot

559 be solely attributed to differences in reaction times, but may instead be related to the heating

560 rates. It should also be noted that the reaction temperature was recorded by $\mathrm{T} 1$ at the bottom of

561 the inner tube, whereas the temperatures at the bottom of the reactor could have been higher,

562 particularly for the less turbulent, lower system flow rates, which could have further impacted on

563 the organic solids conversion.

564 Like the solid yields, the water phase residue yields obtained from the continuous reactor

565 (13.8wt\% to $20.9 \mathrm{w} \%)$ were significantly lower than those obtained from the batch study

566 (20.7 wt\% to $27.7 \mathrm{wt} \%$ ) but in this instance, the residue yields increased with increasing system

567 flow rate, whereas in the batch study they generally reduced as the heating rates were increased.

568 Even more complex trends were obtained for the bio-crude yields. The highest amount of 'light

569 bio-crude' was obtained at the highest flow rate of $6.9 \mathrm{~mL} \mathrm{~min}^{-1}(17.6 \mathrm{wt} \%)$, dropped to a minimum

570 of $13.9 \mathrm{wt} \%$ at $5.0 \mathrm{~mL} \mathrm{~min}^{-1}$, and then increased to $15.4 \mathrm{wt} \%$ at the lowest system flow rate. The

571 'heavy bio-crude' yields followed a different trend, reaching a maximum of $4.9 \mathrm{wt} \%$ at $3.0 \mathrm{~mL} \mathrm{~min}$ -

572 , a minimum of $3.6 \mathrm{wt} \%$ at $5.0 \mathrm{~mL} \mathrm{~min}^{-1}$ and $4.3 \mathrm{wt} \%$ at $6.9 \mathrm{~mL} \mathrm{~min}{ }^{-1}$.

573 A potential explanation for these trends is the contribution of both fast, competitive reactions,

574 favoured by high heating rates, as well as slower reactions, enhanced at higher residence times,

575 to the overall bio-crude formation. The medium flow rate of $5.0 \mathrm{~mL} \mathrm{~min}^{-1}$ was too slow to realise

576 the benefit of high heating rates, whilst the reactor residence time was too short to allow full 
577 conversion of the components in the aqueous phase into the biocrude phase. Slower heating

578 rates and longer reaction times may also have favoured the occurrence of polymerisation 579 reactions, resulting in the formation of heavier bio-crude components, potentially containing 580 greater amounts of aromatics and heteroatoms.

581 This is consistent with the elemental distributions to the biocrude phase obtained for the three 582 system flow rates (Figure $5 b$ ). The bio-crude formed at $3.0 \mathrm{~mL} \mathrm{~min}^{-1}$ contained a lower hydrogen 583 and a higher nitrogen content than the bio-crude phases formed at the higher system flow rates.

584 Even though the carbon recovery of $37.8 \%$ was higher than at the medium flow rate, it was still 585 lower than the carbon recovery at $6.9 \mathrm{~mL} \mathrm{~min}^{-1}(40.8 \%)$. Together with a much higher hydrogen, 586 and lower nitrogen recovery, the best results, both in terms of bio-crude yields and quality, were 587 obtained at the highest system flow rate. However, it is interesting to note that the heavy bio588 crude contained a higher carbon and hydrogen and lower nitrogen content than the light bio-crude 589 (Supplementary information).

590 The carbon retention to the water phase followed a similar trend to the retention in the biocrude, 591 reaching a maximum of $30.8 \%$ at a flowrate of $6.9 \mathrm{~mL} \mathrm{~min}^{-1}$ and a minimum of $26.2 \%$ at the 592 medium flowrate, resulting in total carbon recoveries to the water and bio-crude phases between $59358.6 \%$ and $71.6 \%$. The nitrogen recovery to the water phase was also highest at the highest 594 system flowrate $(86.7 \%)$ resulting in an overall nitrogen recovery of $101.1 \%$.

595 For the highest system flow rate, even the yields of light bio-crude on their own (17.6 wt\%), 596 exceeded the total bio-crude yields obtained from the batch reactor, which demonstrates the 597 advantage of continuous over batch processing. Therefore, research on continuous flow reactors 598 not only provides results which are much more applicable to large-scale industrial processing, but 599 also has the potential to yield improved biocrude yields and product compositions.

600 Further analysis of the combined light bio-crude phase from all continuous reactions revealed a 601 water content of $0.58 \%$, an ash content of $2.3 \mathrm{wt} \%$ and an energy density of $34.9 \mathrm{MJ} \mathrm{kg}^{-1}$. 


\section{Conclusions}

603 Current research on the HTL of microalgae has been mostly restricted to batch reactors due to

604 their lower cost and easier processing, compared to continuous systems. By substituting the high-

605 pressure mechanical pumps used in previous continuous HTL studies with a nitrogen-driven feed

606 delivery system, it was possible to design a lower-cost continuous system, allowing more

607 industrially representative research, compared to the batch reactors commonly used on the lab

608 scale. Data from the continuous monitoring of the system temperature profiles together with

609 constant liquid collection volumes confirmed that the system was able to deliver a constant flow

610 of liquid through the system, with no evidence for gas-breakthrough. In order to prevent the

611 formation of blockages within the reactor, our design incorporated the in-situ collection of the solid

612 reaction product by adapting a double-tube design, which also helped to deliver much higher

613 heating rates, whilst providing extended reaction times. Due to the high viscosity of the biocrude

614 at ambient conditions, it was necessary to collect the liquid product phases at elevated

615 temperatures and pressures and control the system flow rate indirectly, using the outflow of

616 nitrogen and reaction gases from the product collection pots. Using this system it was possible to

617 consistently process $1 \mathrm{~L}$ of a $5 \mathrm{wt} \%$ wastewater-derived algae slurry.

618 Results from the batch study confirmed previous work in the literature, which suggested that

619 increased heating rates could help to improve biocrude yields. This was attributed to the

620 conversion of unstable aqueous phase intermediates during the heating process to form

621 undesired solid or gaseous by-products, before sufficient reaction temperatures were reached to

622 start the bio-crude formation process. Nevertheless, at very high heating rates, biocrude yields

623 reduced sharply and this was ascribed to very short reaction times, insufficient to achieve full

624 biomass conversion.

625 These limitations were not present within the continuous reaction system, which combined fast

626 heating rates with extended reaction times. Consequently, this system was able to produce much 
627 higher biocrude yields and lower solid and water phase residue yields than the batch system.

628 Consistent with previous literature findings, the best results were obtained at the highest system

629 flow rate, although the results suggested a competitive effect on bio-crude formation between fast

630 reactions, favoured by high heating rates, and slower reactions, enhanced at higher reactor

631 residence times.

632 Although maximum overall bio-crude yields of $21.9 \mathrm{wt} \%$ in this study were relatively low, this can

633 be ascribed to a very high algal ash content of 29.9 wt\%, together with a low lipid fraction of

$6347.9 \mathrm{wt} \%$. Given the low cost of this feedstock, the combination of algal wastewater treatment with

635 fuel production via HTL represents a promising economic process, which warrants further 636 investigation.

638 Acknowledgements

639 This work was funded by the Engineering and Physical Sciences Research Council

640 (EP/G03768X/1) and the RAEng through a Newton Fellowship grant (NRCP/1415/176).

641 The authors would like to acknowledge Prof. Rod Scott and Dr Philippe Mozzanega in

642 the Algal Research Group at the University of Bath, for the provision of the wastewater-

643 derived microlalgae, and to Michael J. Allen and Tracey Beacham at the Plymouth

644 Marine Laboratory for conducting the biochemical analysis of the biomass. The data

645 repository can be freely accessed at (https://doi.org/10.15125/BATH-00304).

\section{References}

647 1. S. Raikova, C. D. Le, J. L. Wagner, V. P. Ting and C. J. Chuck, in Biofuels for Aviation 648 Feedstocks, Technology and Implementation, ed. C. J. Chuck, Elsevier, London, 2016.

649 2. Elliott, D.C., Review of recent reports on process technology for thermochemical 650 conversion of whole algae to liquid fuels. Algal Res., 2016. 13: p. 255-263. 
651 3. D. López Barreiro, W. Prins, F. Ronsse and W. Brilman, Hydrothermal liquefaction (HTL)

652 of microalgae for biofuel production: state of the art review and future prospects.

653 Biomass Bioenerg. 2013, 53, 113-127.

654 4. L. Xu, D. W. Wim Brilman, J. A. Withag, G. Brem and S. Kersten, Assessment of a dry

655 and a wet route for the production of biofuels from microalgae: energy balance analysis.

656 Bioresource Technol., 2011, 102, 5113-5122.

657 5. P. Biller, A. B. Ross, S. C. Skill, A. Lea-Langton, B. Balasundaram, C. Hall, R. Riley and

658 C. A. Llewellyn. Nutrient recycling of aqueous phase for microalgae cultivation from the 659 hydrothermal liquefaction process. Algal Res., 2012, 1, 70-76.

660 6. U. Jena, N. Vaidyanathan, S. Chinnasamy and K. C. Das, Evaluation of microalgae 661 cultivation using recovered aqueous co-product from thermochemical liquefaction of 662 algal biomass. Bioresoure Technol., 2011, 102, 3380-3387.

663 7. L. Garcia Alba, C. Torri, D. Fabbri, S. R. A. Kersten and D. W. F. Brilman, Microalgae 664 growth on the aqueous phase from hydrothermal liquefaction of the same microalgae 665 Chem. Eng. J. 2013, 228, 214-223.

666 8. C. J. Chuck, J. L. Wagner and R. W. Jenkins, in Chemical Processes for a Sustainable 667 Future, eds. T. M. Letcher, J. L. Scott and D. A. Patterson, Royal Society of Chemistry, 668 Cambridge, 2015, ch. 16, pp. 425-442.

669 9. Elliott, D.C., et al., Hydrothermal liquefaction of biomass: developments from batch to 670 continuous process. Bioresoure Technol., 2015. 178: p. 147-56.

671 10. J. L. Faeth, P. J. Valdez and P. E. Savage. Fast hydrothermal liquefaction of 672 Nannochloropsis sp. to produce biocrude. Energ. Fuel. 2013, 27, 1391-1398.

673 11. L. Garcia Alba, C. Torri, C. Samorì, J. van der Spek, D. Fabbri, S. R. A. Kersten and D. 674 W. F. Brilman. Hydrothermal treatment (HTT) of microalgae: evaluation of the process 675 as conversion method in an algae biorefinery concept. Energ. Fuel., 2012, 26, 642-657.

676 12. A. Cole, Y. Dinburg, B. S. Haynes, Y. He, M. Herskowitz, C. Jazrawi, M. Landau, X. 677 Liang, M. Magnusson, T. Maschmeyer, A. F. Masters, N. Meiri, N. Neveux, R. de Nys, N. 678 Paul, M. Rabaev, R. Vidruk-Nehemya and A. K. L. Yuen. From macroalgae to liquid fuel 679 via waste-water remediation, hydrothermal upgrading, carbon dioxide hydrogenation and 680 hydrotreating. Energy Environ. Sci., 2016, 9, 1828-1840.

681 13. J. L. Garcia-Moscoso, W. Obeid, S. Kumar and P. G. Hatcher, Flash hydrolysis of 682 microalgae (Scenedesmus sp.) for protein extraction and production of biofuels 683 intermediates. J. Supercrit. Fluid., 2013, 82, 183-190. 
684 14. P. Biller, B. K. Sharma, B. Kunwar and A. B. Ross. Hydroprocessing of bio-crude from 685 continuous hydrothermal liquefaction of microalgae. Fuel, 2015, 159, 197-205.

686 15. B. Patel and K. Hellgardt. Hydrothermal upgrading of algae paste in a continuous flow 687 reactor. Bioresource Technol., 2015, 191, 460-468.

688 16. C. Jazrawi, P. Biller, A. B. Ross, A. Montoya, T. Maschmeyer and B. S. Haynes. Pilot plant testing of continuous hydrothermal liquefaction of microalgae. Algal Res., 2013, 2,

18. D. L. Barreiro, B. R. Gómez, U. Hornung, A. Kruse and W. Prins. Hydrothermal 268-277.

17. D. C. Elliott, T. R. Hart, A. J. Schmidt, G. G. Neuenschwander, L. J. Rotness, M. V.

19. C. M. Beal, L. N. Gerber, D. L. Sills, M. E. Huntley, S. C. Machesky, M. J. Walsh, J. W. Tester, I. Archibald, J. Granados and C. H. Greene. Algal biofuel production for fuels and feed in a 100-ha facility: A comprehensive techno-economic analysis and life cycle assessment. Algal Res., 2015, 10, 266-279.

20. N. D. Orfield, Doctor of Philosophy PhD Thesis, University of Michigan, 2013.

21. R. Sayre. Microalgae: the potential for carbon capture. BioScience, 2010, 60, 722-727.

22. M. K. Lam and K. T. Lee. Microalgae biofuels: a critical review of issues, problems and the way forward. Biotechnol. Adv., 2012, 30, 673-690.

23. M. K. Lam, K. T. Lee and A. R. Mohamed. Current status and challenges on microalgaebased carbon capture. Int. J. Greenhouse Gas Control, 2012, 10, 456-469.

24. S. Raikova, H. Smith-Baedorf, R. Bransgrove, O. Barlow, F. Santomauro, J. L. Wagner, M. J. Allen, C. G. Bryan, D. Sapsford and C. J. Chuck. Assessing hydrothermal liquefaction for the production of bio-oil and enhanced metal recovery from microalgae cultivated on acid mine drainage. Fuel Process. Technol., 2016, 142, 219-227. wastewater treatment high rate algal ponds. Water Sci Technol., 2011, 63, 660-665. Langenhove. Enhanced $\mathrm{CO} 2$ fixation and biofuel production via microalgae: recent developments and future directions. Trends Biotechnol., 2010, 28, 371-380. 
717 27. Aquastat, Food and Agriculture Organization of the United Nations, 2014. Available

718 from: http://www.fao.org/nr/water/aquastat/wastewater/index.stm [28/08/2014].

719 28. Cogan, M. and B. Antizar-Ladislao, The ability of macroalgae to stabilise and optimise

720 the anaerobic digestion of household food waste. Biomass Bioenerg., 2016. 86: p. 146-

$721 \quad 155$.

722 29. K. A. C. C. Taylor. A modification of the phenol/sulfuric acid assay for total

30. E. T. Kostas, D. A. White, C. Du and D. J. Cook, Selection of yeast strains for bioethanol

31. J. Wagner, R. Bransgrove, T. A. Beacham, M. J. Allen, K. Meixner, B. Drosg, V. P. Ting

32. F. Mariotti, D. Tome and P. P. Mirand. Converting nitrogen into protein-beyond 6.25 and Jones' factors Crit. Rev. Food Science Nutrition, 2008, 48, 177-184.

33. A.B. Ross, J.M. Jones, M.L. Kubacki, T. Bridgeman, Classification of macroalgae as fuel and its thermochemical behaviour. Bioresource Technol., 2008. 99(14): p. 6494-504.

34. X. Cheng, M. D. Ooms and D. Sinton, Biomass-to-biocrude on a chip via hydrothermal liquefaction of algae. Lab on a Chip, 2016, 16, 256-260.

35. C. Torri, L. Garcia Alba, C. Samorì, D. Fabbri and D. W. F. Brilman. Hydrothermal treatment (HTT) of microalgae: detailed molecular characterization of HTT oil in view of HTT mechanism elucidation. Energ. Fuel., 2012, 26, 658-671.

36. J. L. Faeth, P. E. Savage, J. M. Jarvis, A. M. McKenna and P. E. Savage. microalgae. AIChE J. 2016, 62, 815-828.

37. C. Tian, Z. Liu, Y. Zhang, B. Li, W. Cao, H. Lu, N. Duan. Hydrothermal liquefaction of harvested high-ash low-lipid algal biomass from Dianchi Lake: effects of operational parameters and relations of products. Bioresource Technol., 2015. 184: p. 336-43.

38. W.T. Chen, Y. Zhang, J. Zhang, G. Yu, L.C. Schideman. Hydrothermal liquefaction of mixed-culture algal biomass from wastewater treatment system into bio-crude oil. Bioresource Technol., 2014. 152: p. 130-9.

39. S. S. Toor, L. Rosendahl and A. Rudolf, Hydrothermal liquefaction of biomass: a review of subcritical water technologies. Energy, 2011, 36, 2328-2342. 
751 40. W. Yang, X. Li, Z. Li, C. Tong and L. Feng. Understanding low-lipid algae hydrothermal 752 liquefaction characteristics and pathways through hydrothermal liquefaction of algal

753 major components: Crude polysaccharides, crude proteins and their binary

754 mixtures.Bioresource Technol., 2015, 196, 99-108.

755

756 


\section{Figure legends}

759 Table 1: Proximate and ultimate analysis of wastewater algae

761 Figure 1: Process schematic for continuous HTL system

762 Figure 2: Effect of reaction temperature on the batch conversion of wastewater-derived algae; (a)

763 overall product distribution, (b) CHN retention in biocrude, (c) CN retention in aqueous phase, 764 calculated from TOC and TN analysis, with the results from ammonium ion analysis superimposed 765 as orange markers Error bars represent the standard deviations of three repeats

766 Figure 3: Effect of heating rate on the batch conversion of wastewater-derived algae; (a) overall

767 product distribution, (b) $\mathrm{CHN}$ retention in biocrude, (c) CN retention to aqueous-phase from TOC

768 and TN analysis, with the results from ammonium ion analysis superimposed as orange markers.

769 Error bars represent the standard deviations of three repeats.

770 Figure 4: Effect of reaction temperature on the continuous liquefaction of wastewater algae; (a)

771 overall product distribution, (b) CHN retention in bio-crude, (c) CN retention to aqueous-phase

772 from TOC and TN analysis, with the results from ammonium ion analysis superimposed as orange

773 markers. Error bars represent standard deviation of two repeats conducted at $320^{\circ} \mathrm{C}$.

774 Figure 5: Effect of feed flowrate on the continuous liquefaction of wastewater algae; (a) overall 775 product distribution, (b) CHN retention in bio-crude, (c) CN retention to aqueous-phase from 776 TOC and TN analysis, with the results from ammonium ion analysis superimposed as orange 777 markers. Error bars represent standard deviation of two repeats conducted at highest flowrate. 778 


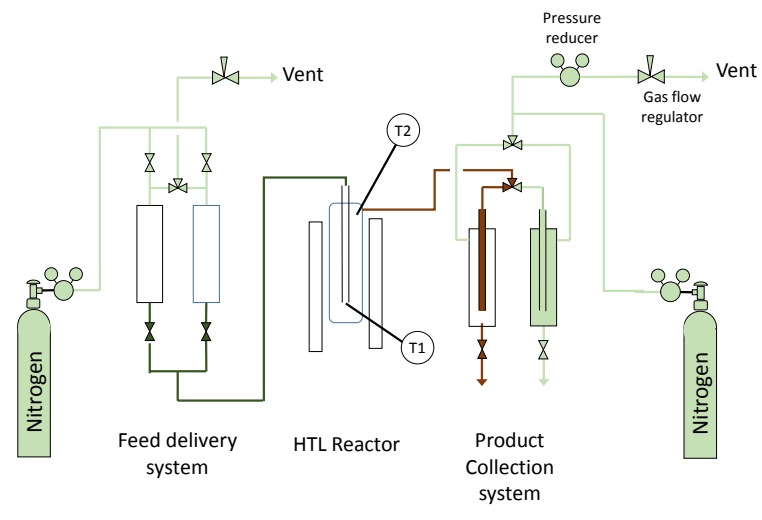

779

780 Figure 1: Process schematic for continuous HTL system

781 
a

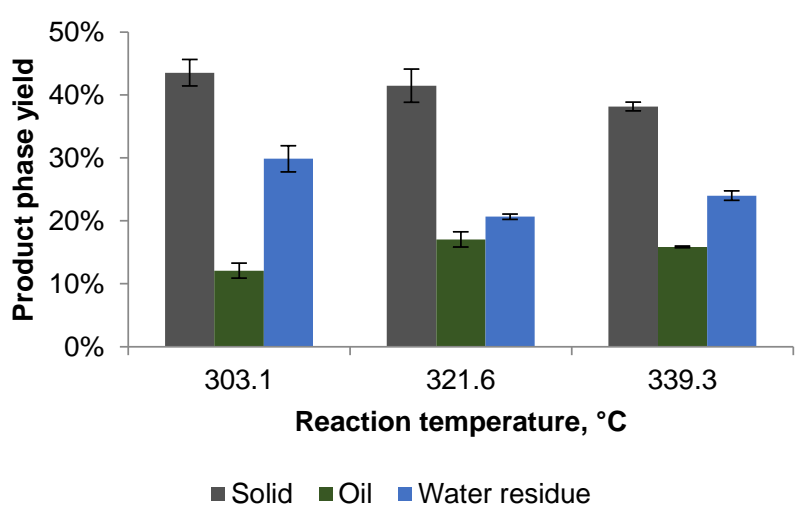

782

b

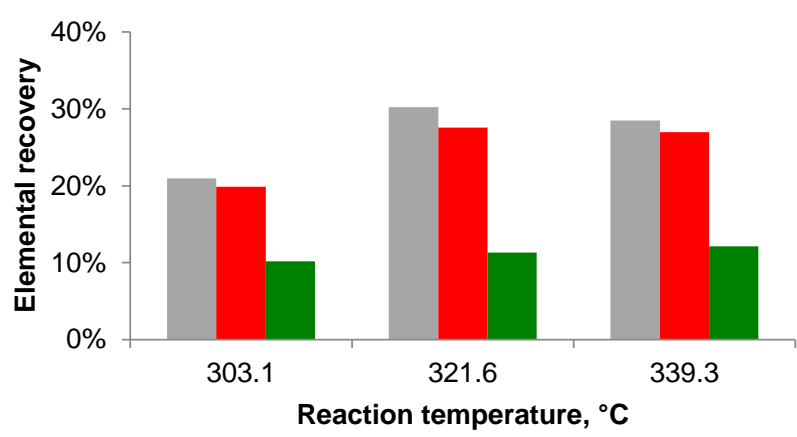

783

C

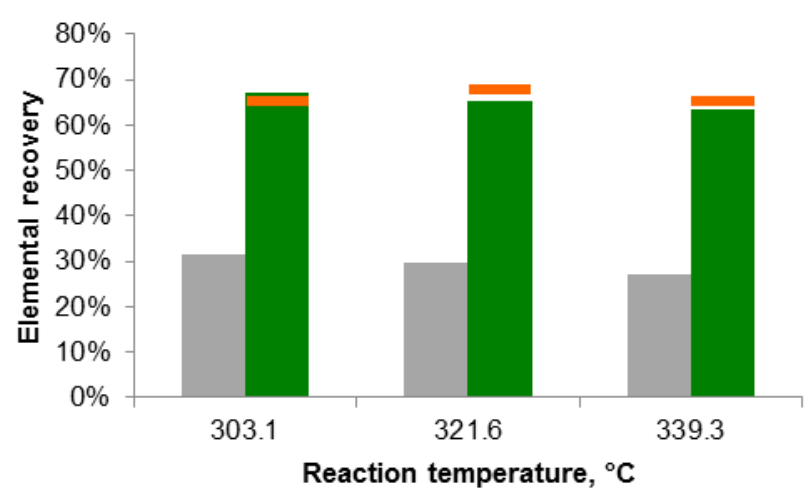

$\square \mathrm{C}=\mathrm{N}$

Figure 2: Effect of reaction temperature on the batch conversion of wastewater-derived algae; (a) overall product distribution, (b) $\mathrm{CHN}$ retention in biocrude, (c) $\mathrm{CN}$ retention in aqueous phase, calculated from TOC and TN analysis, with the results from ammonium ion analysis superimposed as orange markers. Error bars represent the standard deviations of three repeats. 
a

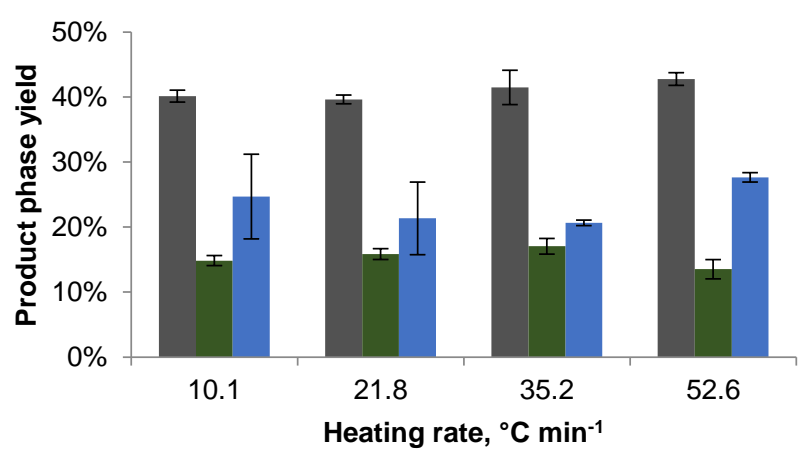

792

$\square$ Solid $n$ Oil $\square$ Water residue

b

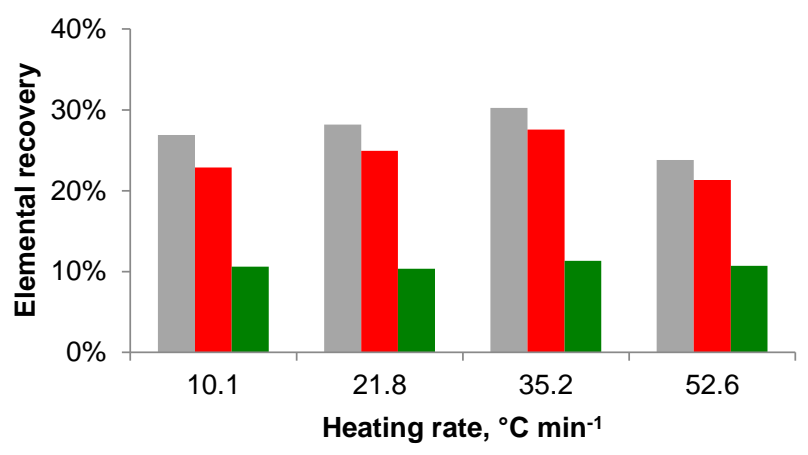

793

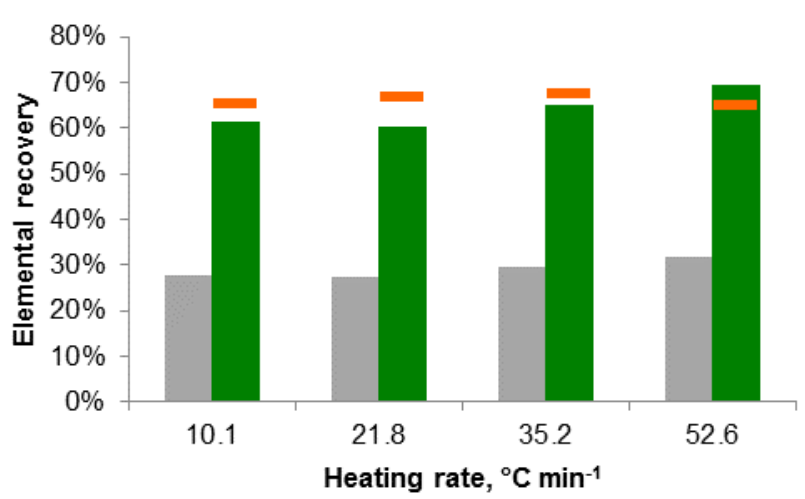

$=\mathrm{C}=\mathrm{N}$

Figure 3: Effect of heating rate on the batch conversion of wastewater-derived algae; (a) overall product distribution, (b) CHN retention in biocrude, (c) $\mathrm{CN}$ retention to aqueous-phase from TOC and TN analysis, with the results from ammonium ion analysis superimposed as orange markers.

798 Error bars represent the standard deviations of three repeats. 
a

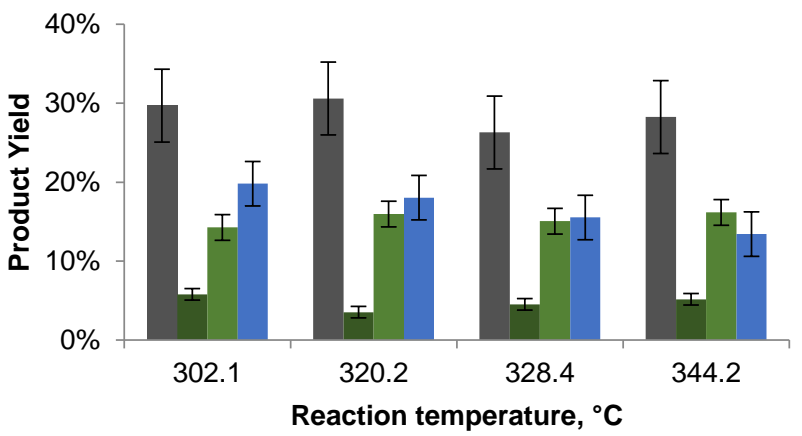

801

- Solid $\quad$ Heavy Oil $\quad$ Light Oil $\quad$ Water phase residue

b

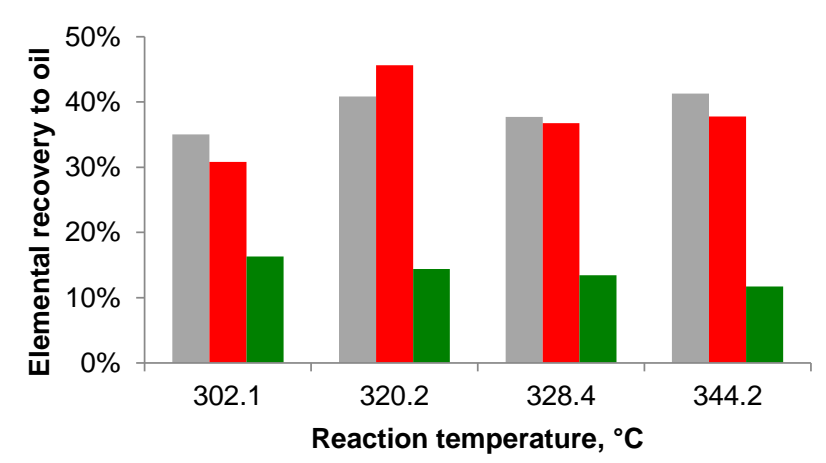

802

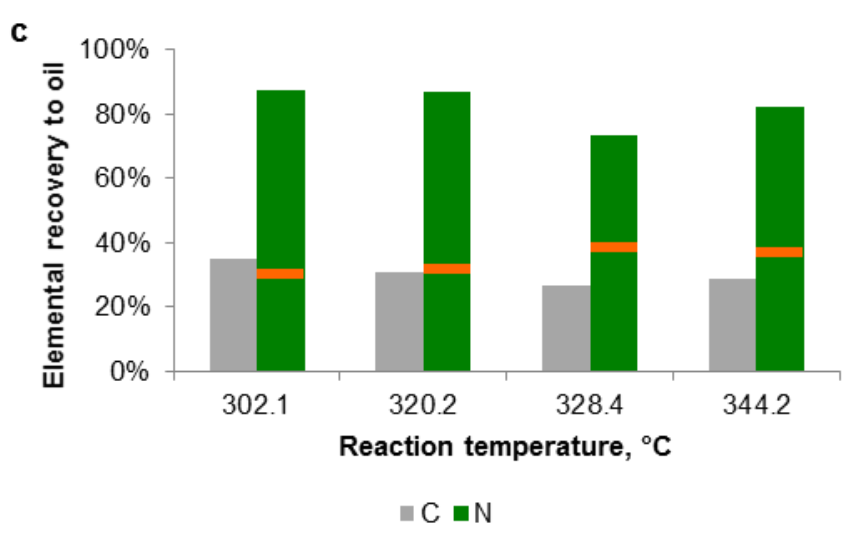

803

Figure 4: Effect of reaction temperature on the continuous liquefaction of wastewater algae; (a) overall product distribution, (b) $\mathrm{CHN}$ retention in bio-oil, (c) $\mathrm{CN}$ retention to aqueous-phase from TOC and TN analysis, with the results from ammonium ion analysis superimposed as orange markers. Error bars represent standard deviation of two repeats conducted at $320{ }^{\circ} \mathrm{C}$. 
a

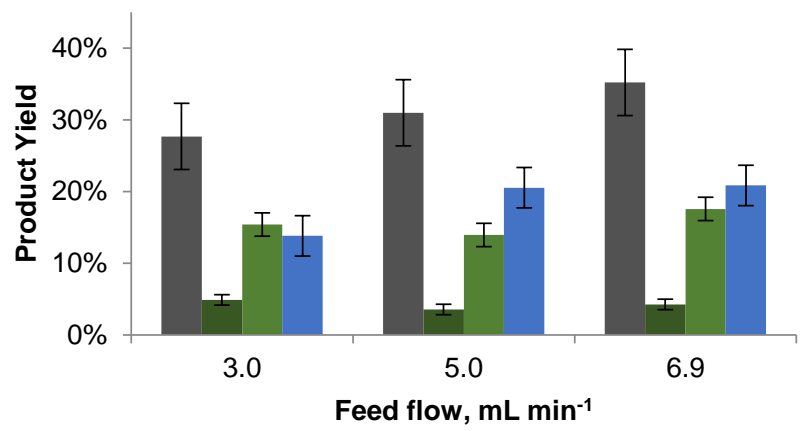

810

घolid $\quad$ Heavy Oil $\square$ Light Oil $\square$ Water phase residue

b

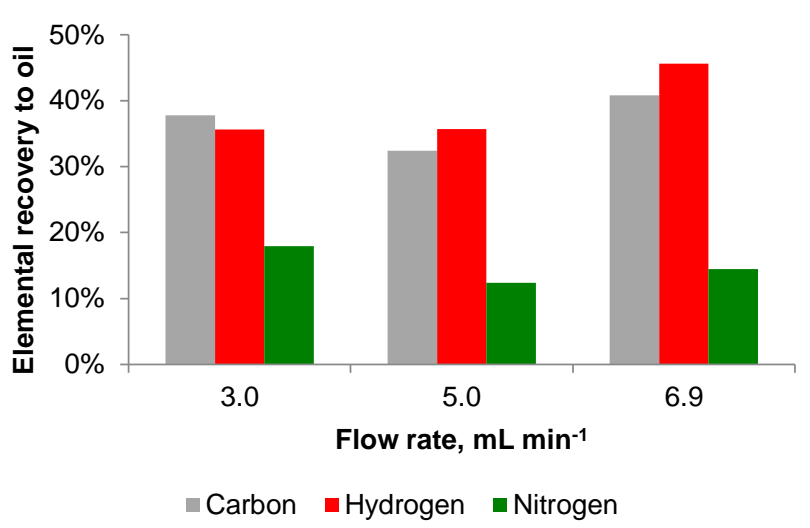

811

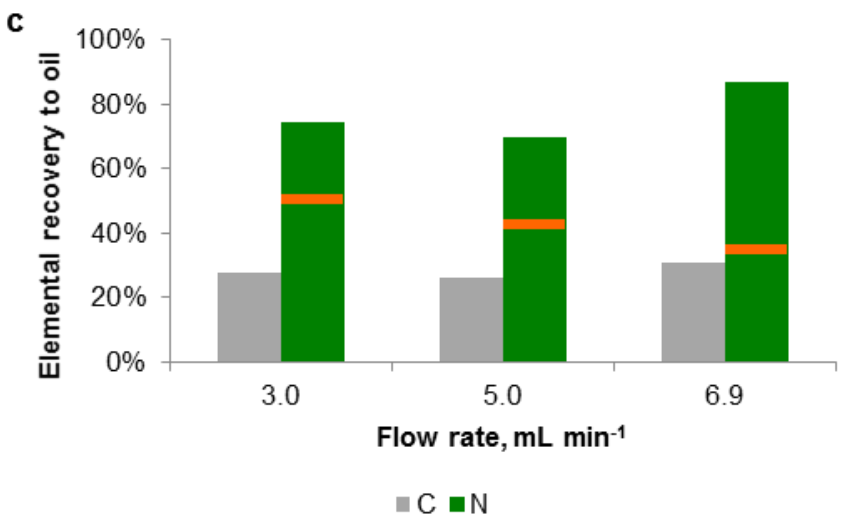

812

813

814

815

816

817

818

819

820

821
Figure 5: Effect of feed flowrate on the continuous liquefaction of wastewater algae; (a) overall product distribution, (b) CHN retention in bio-oil, (c) CN retention to aqueous-phase from TOC and $\mathrm{TN}$ analysis, with the results from ammonium ion analysis superimposed as orange markers. Error bars represent standard deviation of two repeats conducted at highest flowrate. 
